\title{
ARTICLE \\ Synthesis and Characterization of Trivalent Al Substituted Zinc Ferrite using Ethylene Diamine (EDA) as Ligand
}

\section{Soumya Mukherjee*}

Department of Metallurgical Engineering, Kazi NazrulUniversity, PO Kalla More, Asansol, 713340, India

\section{ARTICLE INFO}

Article history

Received: 6 May 2020

Accepted: 25 May 2020

Published Online: 30 October 2020

Keywords:

Al substituted Zinc ferrite

Ethylene Diamine

Thermal analysis

Phase analysis

Strain analysis

\begin{abstract}
Nano domain Al substituted Zinc ferrite was prepared by chemical route using Ethylene Diamine as ligand. High purity precursors nitrate salts of Zinc, $\left.\mathrm{Fe}\left({ }^{3+}\right), \mathrm{Al}^{(3+}\right)$ were utilized along with citric acid which acts as both fuel and complexing agent. Two different molar ratios of $\left.\mathrm{Zn}\left({ }^{2+}\right):\left(\mathrm{Fe}^{3+}\right): \mathrm{Al}^{3+}\right)$ is $1: 1.5: 0.5$ and $1: 1.25: 0.75$. After ensuring proper mix of the solution Ethylene diamine was added dropwise to form a gel like mass with proper $\mathrm{pH}$ control. Before annealing, thermal analysis was carried to determine the crystallization/phase transition zone. Drying was carried in several stages. Initially, gel like mass was obtained after drying at $40^{\circ} \mathrm{C}$ while $\mathrm{pH}$ was about 7. Drying of gel was carried in oil bath at about $90^{\circ} \mathrm{C}$ and powdered mass obtained was grinded followed by auto combustion at $150^{\circ} \mathrm{C}$ for 60 minutes before annealing at $150^{\circ} \mathrm{C}, 350^{\circ} \mathrm{C}, 650^{\circ} \mathrm{C}, 950^{\circ} \mathrm{C}$ for 2 hours to ensure the phase formation. Crystallite size, lattice strain and lattice parameters were studied from XRD analysis.
\end{abstract}

\section{Introduction}

$\mathrm{D}$ ue to presence of unique properties ferrites becomes a material of interest for the last few recent years. Ferrites are noted to have potential applications as storage for electronic, microwave for high resistivity property and also for magnetic applications under high frequency. Ferrites are also noted for application in memory devices, telecommunication devices, ferrofluids, transformer cores, recorders and others. In recent times, spinel ferrites are also noted for applications in biomedical devices, waste water treatment and catalysis of compounds. ${ }^{[1-3]}$ Spinel ferrites can be three types normal spinel, inverse spinel and random spinel ferrite type. Spinel in general represented by $\mathrm{AB}_{2} \mathrm{O}_{4}$ where $\mathrm{A}$ is divalent metal and $\mathrm{B}$ trivalent metal ions respectively. A cations are having one eight of the tetrahedral holes occupied while B cations are having one half of octahedral holes occupied while A-O coordination is tetrahedral one while $\mathrm{B}-\mathrm{O}$ coordination is octahedral one. The tetrahedral sites are occupied by divalent metal cations like $\mathrm{Mg}^{+2}, \mathrm{Co}^{+2}, \mathrm{Zn}^{+2}, \mathrm{Cd}^{+2}, \mathrm{Cu}^{+2}$ while octahedral sites are occupied by trivalent cations like $\mathrm{Fe}^{3+}, \mathrm{Dy}^{3+}, \mathrm{Al}^{3+}, \mathrm{Gd}^{3+}, \mathrm{Eu}^{3+}$ and others. ${ }^{[1]}$ In case of inverse spinel, A site is occupied by trivalent cations and B site is occupied by both divalent and trivalent cations. In several cases of spinel ferrites, an intermediate degree of

*Corresponding Author:

Soumya Mukherjee,

Department of Metallurgical Engineering, Kazi NazrulUniversity, PO Kalla More, Asansol, 713340, India;

Email:smmukherjee3@gmail.com 
inversion among cation site distribution occurs. Due to such inversion among cationic distribution both sites are found to be occupied by both divalent and trivalent cations. Spinel ferrites are ferrimagnetic ordering where magnetic moments of A and B site cations are all aligned parallel to each other leading to net magnetic moment. ${ }^{[4-6]}$ Development of magnetic tunability depend on selection of cations and their distribution at A sites and B sites respectively. Since $\mathrm{Zn}^{+2}$ and $\mathrm{Fe}^{+3}$ ions can be distributed over both $\mathrm{A}$ and $\mathrm{B}$ sites, Zinc ferrite can be represented by $\left(\mathrm{Zn}_{1-\delta} \mathrm{Fe}_{\delta}\right)\left[\mathrm{Zn}_{\delta} \mathrm{Fe}_{2-\delta} \mathrm{O}_{4}\right]$ where portion occupied by round brackets indicate atom position at $\mathrm{A}$ sites where as those occupied by square brackets as $\mathrm{B}$ sites and $\delta$ is called the inversion parameter. The inversion parameter $\delta=0$ for conventionally prepared spinel while the value can reach upto 0.22 for as quenched samples. Nano spinel zinc ferrite exhibits mixed spinel category where the degree of inversion depends on the synthesis process. ${ }^{[6-10]}$ In recent years spinel based oxides are noted to be effective for photocatalyst application specially in UV region. This particular oxide is noted to have some advantage over metal oxide semiconductors which are generally put to use for such applications. A particular case is for Titania as catalyst which is found to be difficult for removal from treated fluid flow thus limiting the application in major scale. Moreover, during catalysis reaction, small crystal size, high surface area of titania undergo some agglomeration thus inhibiting the application. Many industrial applications like alkylation reactions, methylation reactions, $\mathrm{CO}_{2}$ reduction, alcohol decomposition, hydrogen peroxide decomposition and others are noted to be carried effectively by using spinel ferrite as potential catalyst. ${ }^{[11-17]}$ Various routes have been carried for synthesis of ferrite nanoparticles like co-precipitation, solgel, micro-emulsion, ball milling, PVP capping as agent for synthesis, hydrothermal method and so on. ${ }^{[18-22]}$

In the present $\mathrm{Al}$ substituted Zinc ferrite was prepared using Ethylene diamine as ligand. Negligible research is carried till date on synthesis and characterization of Al substituted Zinc ferrite using the ligand as a novel chemical route via complexation reaction.

\section{Experimental Method}

In the present article $\mathrm{AR}$ grade high purity precursors of Zinc ${ }^{2+}, \mathrm{Al}^{3+}, \mathrm{Fe}^{3+}$ nitrates were utilized along with citric acid. 2 molar ratios of $\mathrm{Zn}^{2+}: \mathrm{Fe}^{3+}: \mathrm{Al}^{3+}$ having 1:1.5:0.5 and 1:1.25:0.75 were prepared while citric acid molar ratio was equal to the total molar ratio of metal salts. Citric acid plays the dual role of fuel and complex forming agent. Appropriate amount of nitrate salts were added to the beaker along with optimum amount of distilled water. By means of magnetic stirring saturated solution was prepared and citric acid was added. Ethylene diamine was added dropwise into the resultant solution under stirring conditions. With addition of ethylene diamine the solution becomes highly viscous gel like mass at $\mathrm{pH}$ of about 7 . This transformation was carried at temperature of about $40^{\circ} \mathrm{C}$. Gel was dried at $90^{\circ} \mathrm{C}$ in oil bath followed by grinding of dried gel in agate mortar pestle for autocombustion at $150^{\circ} \mathrm{C}$ for 60 minutes. Auto combustion reaction results in flappy blackish brown mass and it was made to undergo annealing at $150^{\circ} \mathrm{C}, 350^{\circ} \mathrm{C}, 650^{\circ} \mathrm{C}$ and $950^{\circ} \mathrm{C}$ for 2 hours to obtain the desired phase. A part of sample obtained after autocombustion was put for thermal analysis by DSC-TGA (Perkin Elmer, Diamond Pyris) to study crystallization/annealing zone. Phase analysis was carried by XRD (Rigaku, Ultima III) followed by lattice parameters and lattice strain calculation from XRD data.

\section{Result and Discussion}

\subsection{Thermal Analysis}

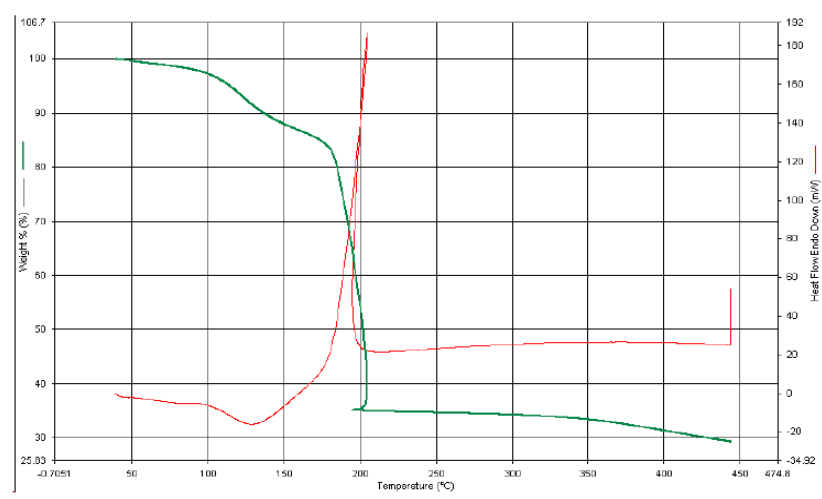

Figure 1. DSC-TGA of gel sample after auto combustion at $150^{\circ} \mathrm{C}$ having $\mathrm{Al}^{3+} 0.5$ molar ratio using Ethylene diamine as ligand

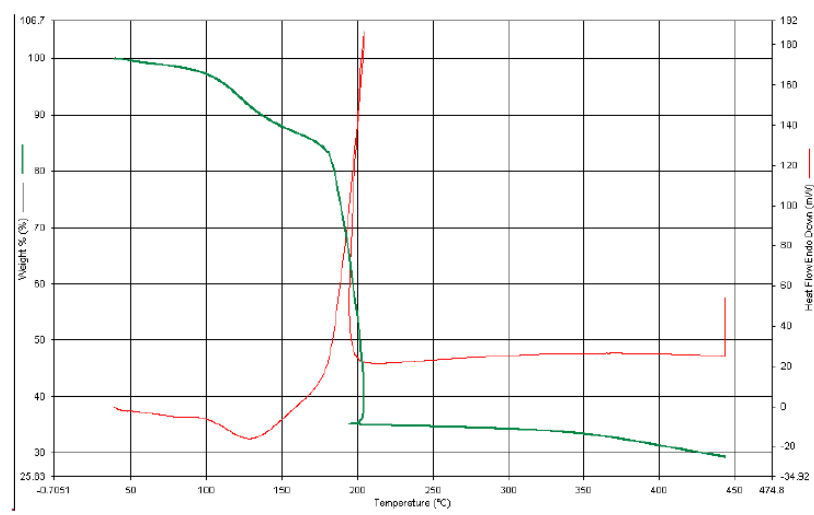

Figure 2. DSC-TGA of gel sample after auto combustion at $150^{\circ} \mathrm{C}$ having $\mathrm{Al}^{3+} 0.75$ molar ratio using Ethylene diamine as ligand

From DSC-TGA analysis it is evident that drastic 
weight loss occurs in two stages upto $200^{\circ} \mathrm{C}$ followed by flat weight changes. For both samples $1 \& 2$, initial $10 \%$ weight change is observed till $140^{\circ} \mathrm{C}$ while $50 \%$ weight change is noted from 140 to $200^{\circ} \mathrm{C}$ with a sharp exothermic reaction noted at about $180^{\circ} \mathrm{C}$. Weight losses are attributed to water of crystallization along with slight combustion reaction indicated while slight weight change is noted from $300^{\circ} \mathrm{C}$ to $400^{\circ} \mathrm{C}$. The possible reaction at about $180^{\circ} \mathrm{C}$ would be the decomposition of complexing agent assisting the $\mathrm{Al}$ substituted Zinc ferrite formation. For both samples decomposition of complex initiates at about $150^{\circ} \mathrm{C}$ and stops at $200^{\circ} \mathrm{C}$.

\subsection{XRD Analysis}

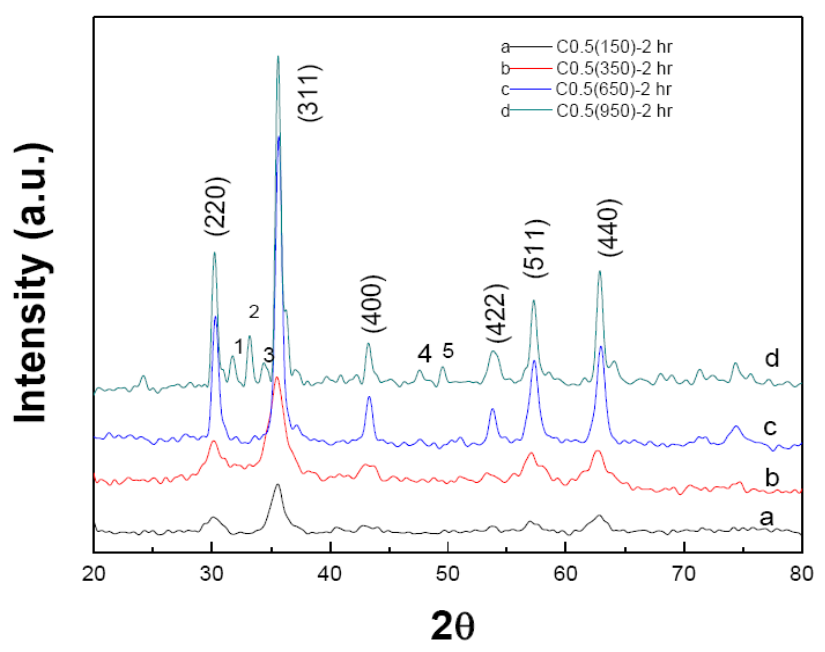

Figure 3. XRD plot of $\mathrm{x}=0.5 \mathrm{Al}$ molar ratio substituted Zinc Ferrite at a) $150^{\circ} \mathrm{C}$, b) $350^{\circ} \mathrm{C}$, c) $650^{\circ} \mathrm{C}$ and d) $950^{\circ} \mathrm{C}$ for 2 hours using EDA as ligand

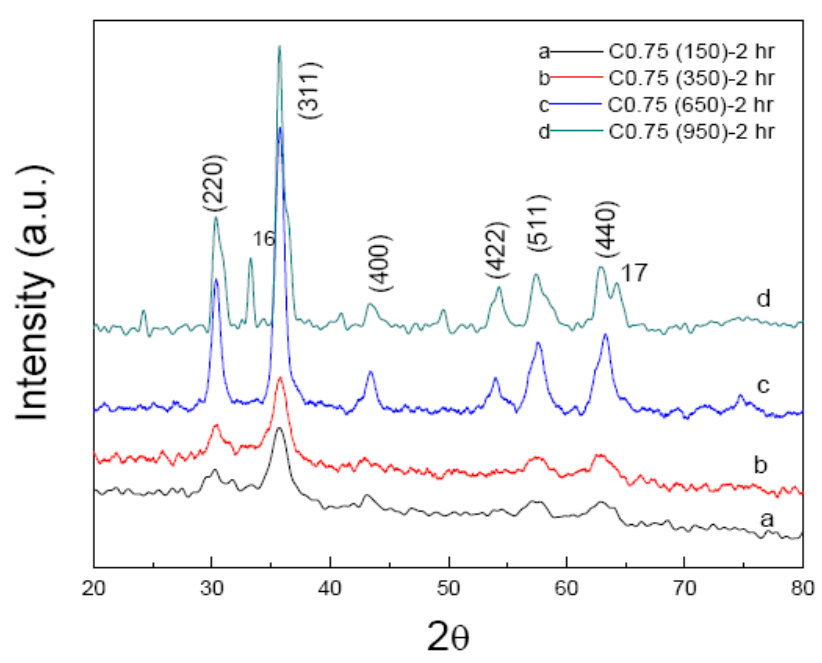

Figure 4. XRD plot of $x=0.75 \mathrm{Al}$ molar ratio substituted Zinc Ferrite at a) $150^{\circ} \mathrm{C}$, b) $350^{\circ} \mathrm{C}$, c) $650^{\circ} \mathrm{C}$ and d) $950^{\circ} \mathrm{C}$ for 2 hours using EDA as ligand
XRD analysis (Figure $3 \& 4$ ) exhibits crystallographic planes after annealing at $150^{\circ} \mathrm{C}, 350^{\circ} \mathrm{C}, 650^{\circ} \mathrm{C}$ and $950^{\circ} \mathrm{C}$ for 2 hours soaking period. At lower temperature having fixed soaking period, peaks noted are broad with humps indicating slight amorphous nature. With increase in temperature peak intensity rises indicating better crystallinity. Prominent peaks are noted along (22), (311), (400), (511) and (440) planes which have thermodynamic stability for growth. Crystallite size is estimated using scherrers formula and got compared with JCPDS card No 82-1048. Crystallite size is noted to be about $8.31 \mathrm{~nm}, 5.45 \mathrm{~nm}, 13.21 \mathrm{~nm}$ and $16.29 \mathrm{~nm}$ for $\mathrm{x}=0.5$ mole $\mathrm{Al}^{3+}$ substitution at $150^{\circ} \mathrm{C}, 350^{\circ} \mathrm{C}, 650^{\circ} \mathrm{C}$ and $950^{\circ} \mathrm{C}$ for 2 hours respectively. Increase in crystallite size is due to enhanced diffusion of atoms across grain boundaries due to thermal activation. All of the peaks got indexed with $\mathrm{ZnFe}_{1.5} \mathrm{Al}_{0.5} \mathrm{O}_{4}$ (Figure 3) and with $\mathrm{ZnFe}_{1.25}$ $\mathrm{Al}_{0.75} \mathrm{O}_{4}$ (Figure 4) in the temperature range of $150^{\circ} \mathrm{C}$ to $650^{\circ} \mathrm{C}$ for 2 hours soaking. In case of $\mathrm{ZnFe}_{1.5} \mathrm{Al}_{0.5} \mathrm{O}_{4}$ at higher temperature of $950^{\circ} \mathrm{C}$ minor amounts of $\mathrm{Fe}_{2} \mathrm{O}_{3}$ peaks are noted (peak indicated as 1,2,4,5) in Figure 3 while peak no 3 is for $\mathrm{FeO}$ as analyzed by XRD after verifying with JCPDS data card of respective individual elemental oxides of the synthesized compound. From Figure 4 it is noted that for higher mole fraction of $\mathrm{Al}$ substitution only $\mathrm{Fe}_{2} \mathrm{O}_{3}$ is formed for 2 small peaks (peak indicate as 16,17 ) while no $\mathrm{FeO}$ is formed in this case. Similar to the case of $\mathrm{x}=0.5$ mole fraction of $\mathrm{Al}^{3+}$ substitution, substitution with $\mathrm{x}=0.75$ mole fraction also exhibits increase in crystallite size with temperature for fixed soaking period of 2 hours respectively. Crystallite size is noted to be about $6.33 \mathrm{~nm}, 6.47 \mathrm{~nm}$, $10.50 \mathrm{~nm}, 16.69 \mathrm{~nm}$ for $150^{\circ} \mathrm{C}, 350^{\circ} \mathrm{C}, 650^{\circ} \mathrm{C}$ and $950^{\circ} \mathrm{C}$ respectively. For both case, strong crystalline peaks are noted with increase in temperature. Moreover, with higher Al substitution $(x=0.75)$ for the same Ethylene diamine ligand having same soaking temperature and soaking period higher purity of the compound is noted in compare to lower $\mathrm{Al}$ substitution $(\mathrm{x}=0.5)$. Using Williamson hall analysis crystallite size is estimated to be $3.38 \mathrm{~nm}, 11.9 \mathrm{~nm}, 20.8 \mathrm{~nm}, 17.86 \mathrm{~nm}$ for annealing at $150^{\circ} \mathrm{C}, 350^{\circ} \mathrm{C}, 650^{\circ} \mathrm{C}, 950^{\circ} \mathrm{C}$ for 2 hours with 0.5 molar $\mathrm{Al}^{3+}$ substitution. In case of 0.75 molar $\mathrm{Al}^{3+}$ substitutions for similar temperature and soaking condition crystallite size calculated using Williamson hall plot is observed to be $4.85 \mathrm{~nm}, 15.38 \mathrm{~nm}, 25.64 \mathrm{~nm}$ and $66.67 \mathrm{~nm}$ respectively.

DOI: https://doi.org/10.30564/omms.v2i2.1863 

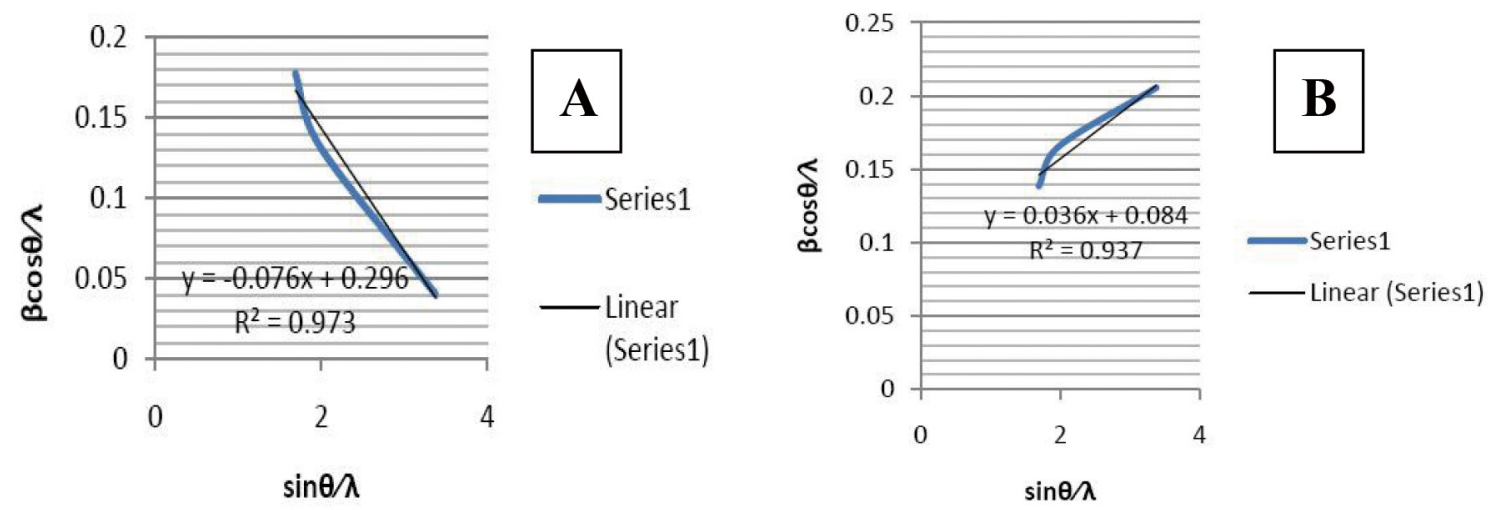

Figure 5. Plot of $\beta \operatorname{Cos} \theta / \lambda$ and $\operatorname{Sin} \theta / \lambda$ for sample with $\mathrm{x}=0.5 \mathrm{Al}$ substitution using $\mathrm{EDA}$ as ligand at $\left.\mathrm{A}) 150^{\circ} \mathrm{C} \& \mathrm{~B}\right)$ $350^{\circ} \mathrm{C}$ for 2 hours
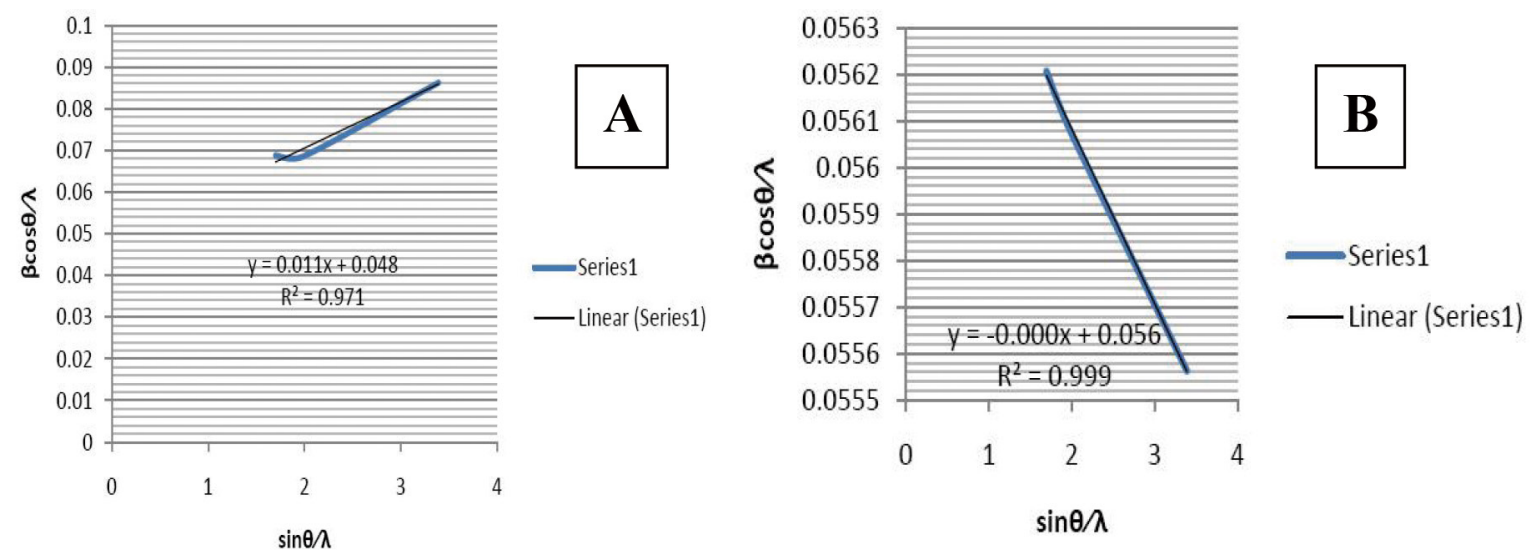

Figure 6. Plot of $\beta \operatorname{Cos} \theta / \lambda$ and $\operatorname{Sin} \theta / \lambda$ for sample with $\mathrm{x}=0.5 \mathrm{Al}$ substitution using EDA as ligand at $\left.\mathrm{A}) 650^{\circ} \mathrm{C} \& \mathrm{~B}\right)$ $950^{\circ} \mathrm{C}$ for 2 hours

It is observed from the plot of $\beta \operatorname{Cos} \theta / \lambda \mathrm{Vs} \operatorname{Sin} \theta /$ $\lambda$ (Figure $5 \&$ Figure 6) values of $\mathrm{R}^{2}$ is close to unity. Thus the plot is close to linearity suggesting that the particle size would be towards monodispersive nature.
These above plots indicate that the particle size does not represent scatter in observation or in other words narrow particle size distribution is possible.
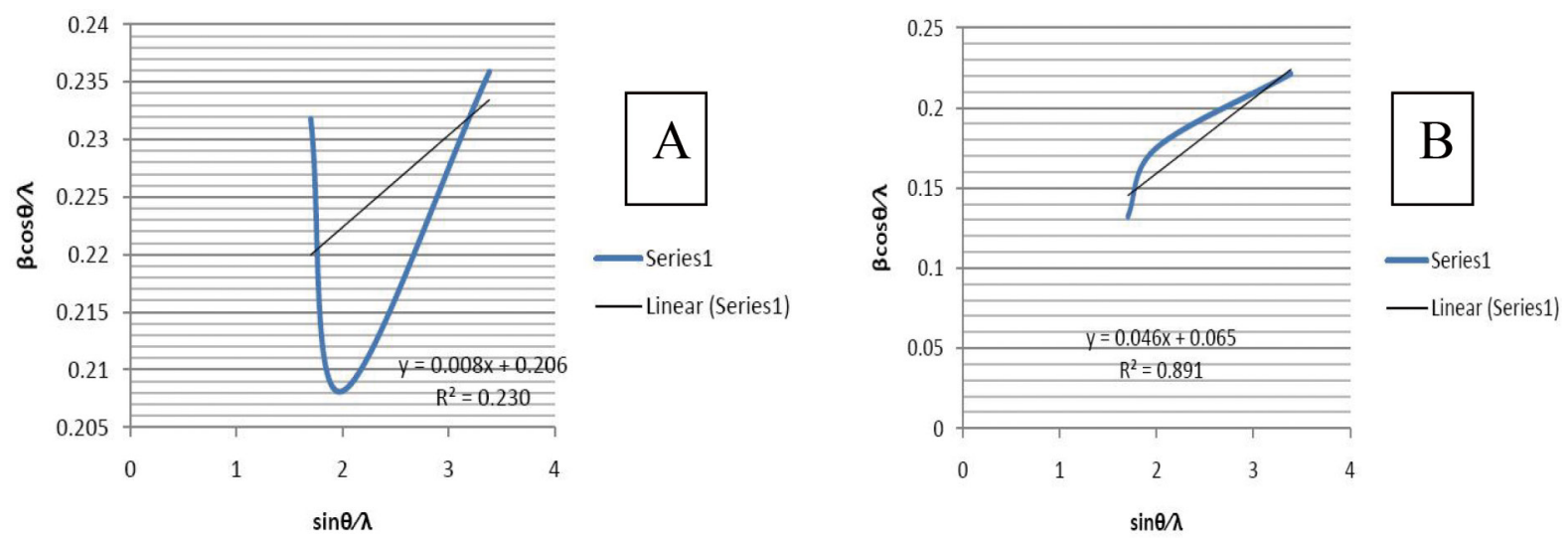

Figure 7. Plot of $\beta \operatorname{Cos} \theta / \lambda$ and $\operatorname{Sin} \theta / \lambda$ for sample with $\mathrm{x}=0.75 \mathrm{Al}$ substitution using $\mathrm{EDA}$ as ligand at $\left.\mathrm{A}) 150^{\circ} \mathrm{C} \& \mathrm{~B}\right)$ $350^{\circ} \mathrm{C}$ for 2 hours 

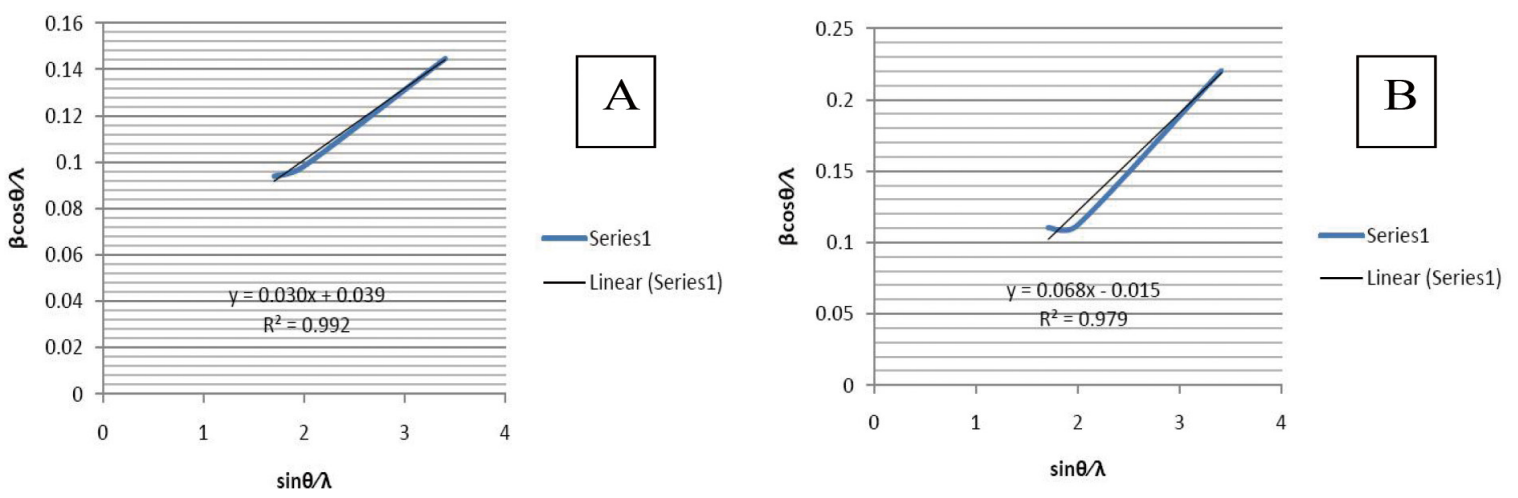

Figure 8. Plot of $\beta \operatorname{Cos} \theta / \lambda$ and $\operatorname{Sin} \theta / \lambda$ for sample with $x=0.75 \mathrm{Al}$ substitution using EDA as ligand at $\mathrm{A}) 650^{\circ} \mathrm{C} \& \mathrm{~B}$ ) $950^{\circ} \mathrm{C}$ for 2 hours

It is observed from the plot of $\beta \operatorname{Cos} \theta / \lambda$ Vs $\operatorname{Sin} \theta / \lambda$ (Figure $7 \&$ Figure 8) values of $\mathrm{R}^{2}$ is close to unity but in one case the deviation is far away from unity. Observations of plot close to linearity suggest that the particle size would be towards monodispersive nature. One major deviation observed in linearity may be due to higher $\mathrm{Al}$ substitution in Zinc ferrite and size difference between $\mathrm{Al}^{3+}(0.53 \AA)$ and $\mathrm{Fe}^{3+}(0.64 \AA)$ ions. Higher proportion of $\mathrm{Al}^{3+}$ substitution may leads to prominent size distribution difference and strain effect on the matrix of the compound.

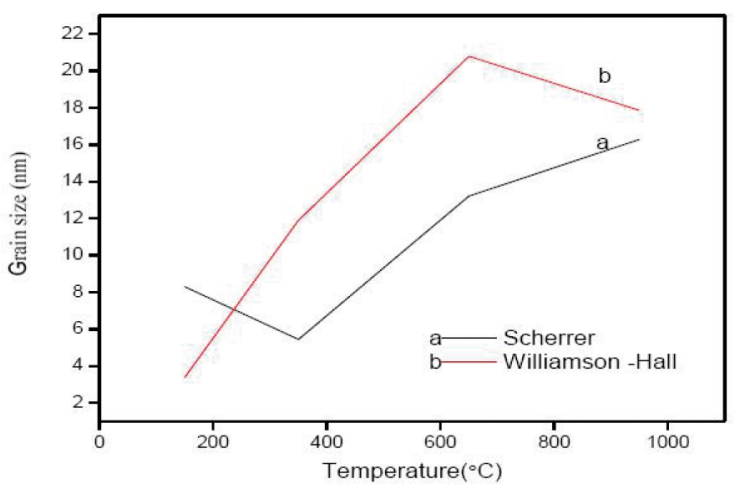

Figure 9. Variation of grain size $\mathrm{Vs}$ temperature for $\mathrm{ZnAl}_{05} \mathrm{Fe}_{1.5} \mathrm{O}_{4}$ using EDA as ligand along with comparison of Scherrers and Williamson Hall data

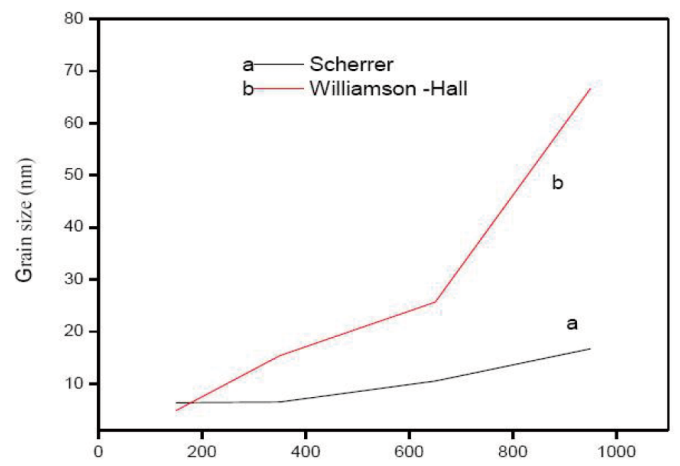

Figure 10. Variation of grain size Vs temperature for $\mathrm{ZnAl}_{075} \mathrm{Fe}_{1.25} \mathrm{O}_{4}$ using EDA as ligand along with comparison of Scherrers and Williamson Hall data
Both Figure $9 \&$ Figure 10 exhibits variation of grain size with temperature using EDA as ligand. Both higher and lower substitution of $\mathrm{Al}^{3+}$ exhibits almost same trend for both Scherrer and Williamson hall plot. The nature of graph is following the same trend which is noted for grain size growth with increase in temperature due to enhanced diffusion.

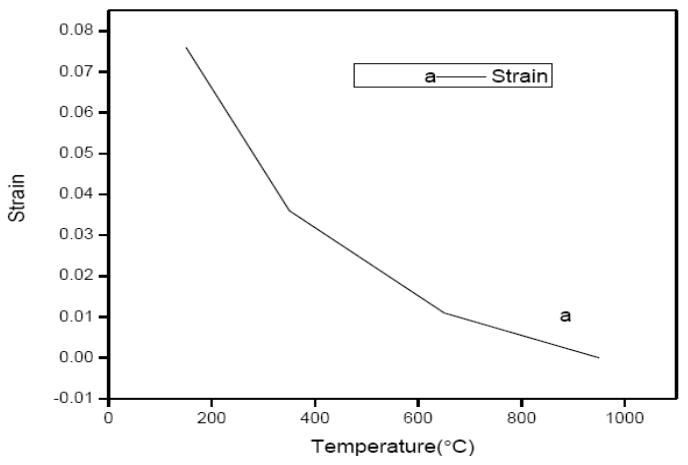

Figure 11. Variation of lattice strain for $\mathrm{ZnAl}_{05} \mathrm{Fe}_{1.5} \mathrm{O}_{4}$ using EDA as ligand with temperature

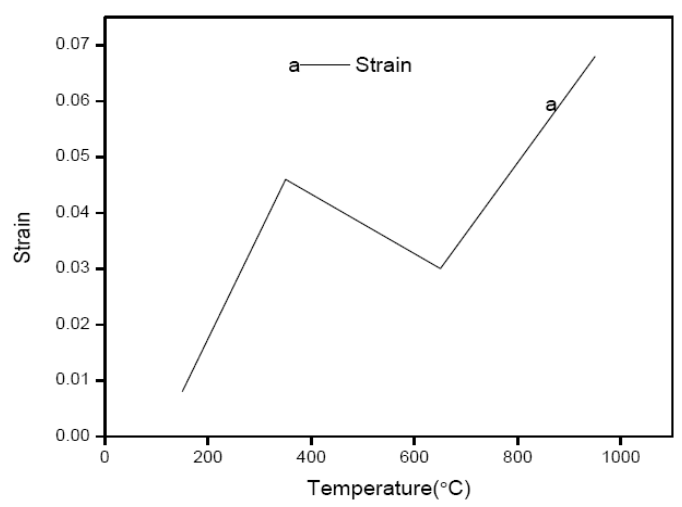

Figure 12. Variation of lattice strain for $\mathrm{ZnAl}_{075} \mathrm{Fe}_{1.25} \mathrm{O}_{4}$ using EDA as ligand with temperature

Figure 11 \& Figure 12 exhibits lattice strain variation for both Al substituted $(\mathrm{x}=0.5)$ and $(\mathrm{x}=0.75)$ mole fraction on Zn-ferrite matrix with annealing temperature for fixed soaking period of 2 hours. For $\mathrm{x}=.5$ mole $\mathrm{Al}$ 
substituted Zinc ferrite strain decreases with temperature due to relaxation a general observation. But for $\mathrm{x}=0.75$ mole Al substitution, lattice strain variation with temperature is irregular type and compare to previous case (Figure 7A) strain factor increases. The above result is in correspondence to XRD phase formation and $\mathrm{R}^{2}$ value noted from $\beta \operatorname{Cos} \theta / \lambda$ and $\operatorname{Sin} \theta / \lambda$ plot of samples synthesized and analysed by XRD at various temperature. The value of $R^{2}$ is quite regular with close to unity for all case for $\mathrm{x}=0.5$ mole $\mathrm{Al}$ substitution but for higher substitution, the value is sporadic in one case while close to unity for other cases. The exact values of lattice strain for $\mathrm{ZnAl}_{05} \mathrm{Fe}_{1.5} \mathrm{O}_{4}$ is about $0.076,0.036,0.011$ and 0.02 respectively with increase in annealing temperatures $150^{\circ} \mathrm{C}, 350^{\circ} \mathrm{C}, 650^{\circ} \mathrm{C}$ and $950^{\circ} \mathrm{C}$ finally. Similarly for $\mathrm{ZnAl}_{075} \mathrm{Fe}_{1.25} \mathrm{O}_{4}$ using EDA as ligand, lattice strain is noted to be about $0.00815,0.0465,0.0388$ and 0.0682 respectively with increase in annealing temperatures $150^{\circ} \mathrm{C}, 350^{\circ} \mathrm{C}, 650^{\circ} \mathrm{C}$ and $950^{\circ} \mathrm{C}$.

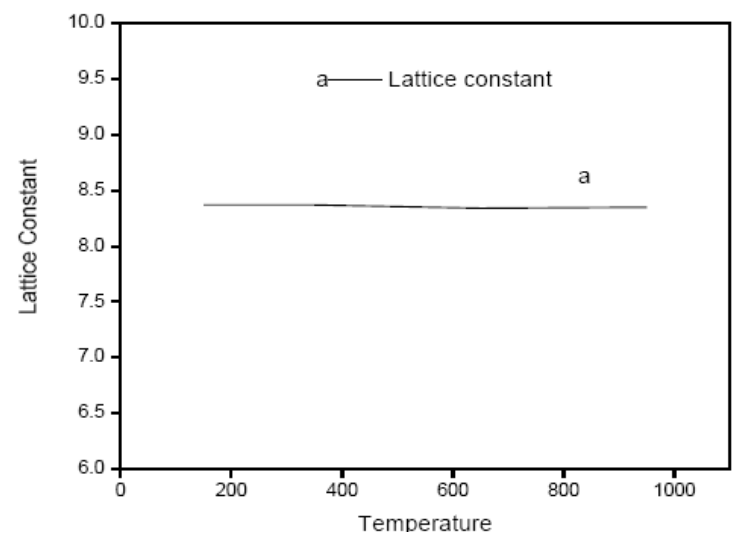

Figure 13. Variation of Lattice constant for $\mathrm{ZnAl}_{05} \mathrm{Fe}_{1.5} \mathrm{O}_{4}$ using EDA as ligand with temperature

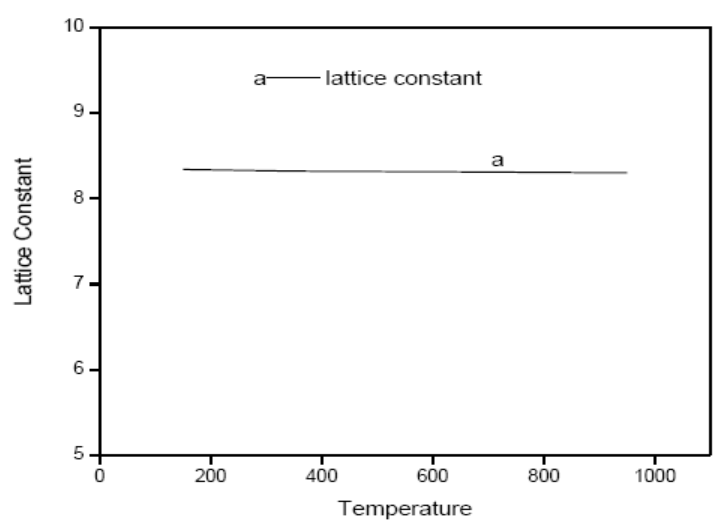

Figure 14. Variation of Lattice Constant for $\mathrm{ZnAl}_{075} \mathrm{Fe}_{1.25} \mathrm{O}_{4}$ using EDA as ligand with temperature

Figure $13 \& 14$ reveals the variation of lattice constant for $\mathrm{Al}$ substituted Zinc ferrite ( $\mathrm{x}=0.5,0.75)$ using $\mathrm{EDA}$ as ligand with similar temperature variation. For both case lattice constant variation is similar trend having constant value throughout irrespective of $\mathrm{Al}^{3+}$ substitution $(\mathrm{x}=0.5$ mole fraction, $x=0.75$ mole fraction) noted to be around $8.40 \AA$. Actual values of lattice strain calculated from $\beta \operatorname{Cos} \theta / \lambda$ and $\operatorname{Sin} \theta / \lambda$, strain is calculated while $d$ spacing is noted from JCPDS along with planes of direction. Using the formula from Braggs Law lattice constant is calculated as $d=a \sqrt{ }\left(h^{2}+K^{2}+l^{2}\right)$ where a is the lattice constant of the required crystal structure, $\mathrm{h}, \mathrm{k}, \mathrm{l}$ are the planes of orientation. From calculations, it is noted that there is minor reduction in lattice constant as $\mathrm{Al}^{3+}$ get substituted for $\mathrm{Fe}^{3+}$ in the matrix of Zinc ferrite. Cationic radius of $\mathrm{Al}^{3+}=0.53 \AA$ while that of $\mathrm{Fe}^{3+}=0.64 \AA$ which indicates clearly that substitution will leads to minor reduction in lattice constant. The exact values of lattice constant for $\mathrm{x}=0.5$ mole $\mathrm{Al}^{3+}$ substitution with fixed EDA as ligand are noted as $8.37 \AA, 8.34 \AA$ and $8.35 \AA$ for ascending order of four different annealing temperatures. Similarly, for $\mathrm{x}=0.75 \mathrm{~mole}^{3{ }^{3+}}$ substitution lattice parameters are noted as $8.34 \AA, 8.32 \AA, 8.31 \AA$ and $8.30 \AA$ for ascending order of four different annealing temperatures.

\section{Conclusions}

Al substituted Zinc ferrite having $x=0.5, .75$ molar ratio of stoichometry $\mathrm{ZnAl}_{x} \mathrm{Fe}_{2-\mathrm{x}} \mathrm{O}_{4}$ is synthesized using Ethylene diamine as ligand by complexation reaction at about $180^{\circ} \mathrm{C}$ followed by annealing $150^{\circ} \mathrm{C}, 350^{\circ} \mathrm{C}, 650^{\circ} \mathrm{C}$ and $950^{\circ} \mathrm{C}$ for 2 hours. Thermal analyses by DSC-TGA are carried to determine the complexation reaction while the crystallite size is estimated to be about 5.45 to $16.69 \mathrm{~nm}$ for all cases by Scherrers formula. From strain calculation, plotting of $\sin \theta / \lambda$ and $\beta \cos \theta / \lambda$ indicate coefficient of regression $\mathrm{R}^{2}$ to be close to unity for most cases. In case of 0.5 molar fraction of $\mathrm{Al}^{3+}$ substitution $\mathrm{R}^{2}$ is close to unity with negligible deviation and such is possible with particle size having monodispersive nature. Similar observation is observed for 0.75 mole $\mathrm{Al}^{3+}$ substitution with only one deviation in linearity at lower temperature of annealing. Grain size is noted to be increasing with temperature for both Scherrers and Williamson-Hall calculations for both molar $\mathrm{Al}^{3+}$ substitutions. Strain induced at lattice within the matrix is found to be decreasing with increase in temperature for both molar substitutions. Lattice constant is found to be nearly constant for molar ratio variation of 0.5 and 0.75 at Fe site. In reality there is slight decrease in lattice parameter since $\mathrm{Al}^{3+}$ radius is smaller than $\mathrm{Fe}^{3+}$ at $\mathrm{B}$ site.

\section{References}

[1] Simab Gul, Muhammad Asif Yousuf, Asima Anwar, 
Muhammad Farooq Warsi, Philips O Agboola, Imran Shakir, Muhammad Shahid. Al Substituted Zinc Spinel Ferrite Nanoparticles: Preparation and Evaluation of Structural, Electrical, Magnetic and Photocatalytic Properties. Ceramics International, 2020. https://doi.org/10.1016/j.ceramint.2020.02.228

[2] J. Hu, X. Liu, X. Kan, S. Feng, C. Liu, W. Wang, K.M.U. Rehman, M. Shazed, S. Zhou, Q. Wu. Characterization of Texture and Magnetic Properties of $\mathrm{Ni}_{0.5} \mathrm{Zn}_{0.5} \mathrm{Ti}_{\mathrm{x}} \mathrm{Fe}_{2-\mathrm{x}} \mathrm{O}_{4}$ Spinel Ferrites. Journal of Magnetism and Magnetic Materials, 2019, 489(1). https://doi.org/10.1016/j.jmmm.2019.165411

[3] Li'an Han, Wanlin Zhai, Bing Bai, Huaze Zhu, Jing Yang, Zhengxin Yan, Tao Zhang. Critical behavior in $\mathrm{Ni}_{0.15} \mathrm{Cu}_{0.15} \mathrm{Zn}_{0.7} \mathrm{Fe}_{2} \mathrm{O}_{4}$ spinel ferrite. Ceramics International, 2019, 45(11): 14322-14326.

[4] Chandan Upadhyay, H.C. Verma. Cation distribution in nanosized Ni-Zn ferrites. Journal of Applied Physics, 2004, 95(10): 5746-5751.

[5] Xiuling Jiao, Dairong Chen, Yong Hu. Hydrothermal synthesis of nanocrystalline $\mathrm{M}_{x} \mathrm{Zn}_{1-x} \mathrm{Fe}_{2} \mathrm{O}_{4}(\mathrm{M}=\mathrm{Ni}$, $\mathrm{Mn}, \mathrm{Co} ; x=0.40-0.60)$ powders. Materials Research Bulletin, 2002, 37(9): 1583-1588.

[6] Viorica Musat Bujoreanu, Eugen Segal. On the dehydration of mixed oxides powders coprecipitated from aqueous solutions. Solid State Sciences, 2001, 3(4): 407-415.

[7] Xiao Jia, Dairong Chen, Xiuling Jiao, Tao He, Hanyu Wang, Wei Jiang. Monodispersed Co, Ni-Ferrite Nanoparticles with Tunable Sizes: Controlled Synthesis, Magnetic Properties, and Surface Modification. The Journal of Physical Chemistry C, 2008, 112(4): 911-917.

[8] Adriana S. Albuquerque, José D. Ardisson, Waldemar A. A. Macedo. Nanosized powders of NiZn ferrite: Synthesis, structure, and magnetism. Journal of Applied Physics, 2002, 87(9): 4352-4357.

[9] Wei-Chih Hsu, S.C. Chen, P.C. Kuo, C.T. Lie, W.S. Tsai. Preparation of NiCuZn ferrite nanoparticles from chemical co-precipitation method and the magnetic properties after sintering. Materials Science and Engineering B, 2004, 111(2-3): 142-149.

[10] Chao Liu, Bingsuo Zou, Adam J. Rondinone, Z. John Zhang. Chemical Control of Superparamagnetic Properties of Magnesium and Cobalt Spinel Ferrite Nanoparticles through Atomic Level Magnetic Couplings. Journal of the American Chemical Society, 2000, 122(26): 6263-6267.

[11] A.I. Borhan, P. Samoila, Vasile Hulea, A.R. Iordan, M.N. Palamaru. Effect of $\mathrm{Al}^{3+}$ substituted zinc ferrite on photocatalytic degradation of Orange I azo dye. Journal of Photochemistry and Photobiology A:
Chemistry, 2014, 279(1): 17-23.

[12] M. Bodzek, M. Rajca. Photocatalysis in the treatment and disinfection of water. Part I. Theoretical backgrounds. Ecological Chemistry and Engineering S, 2012, 19(4): 489-512.

[13] M. Yazdanbakhsh, I. Khosravi, E.K. Goharshadi, A. Youssefi. Fabrication of nanospinel $\mathrm{ZnCr}_{2} \mathrm{O}_{4}$ using sol-gel method and its application on removal of azo dye from aqueous solution. Journal of Hazardous Materials, 2010, 184(1-3): 684-689.

[14] E. Manova, T. Tsoncheva, D. Paneva, I. Mitov, K. Tenchev, L. Petrov. Mechanochemically synthesized nano-dimensional iron-cobalt spinel oxides as catalysts for methanol decomposition. Applied Catalysis A, 2004, 277(1-2): 119-127.

[15] W. Walerczyk, M. Zawadzki, H. Grabowska. Solvothermal synthesis and catalytic properties of nanocrystalline $\mathrm{ZnFe}_{2-\mathrm{x}} \mathrm{Al}_{\mathrm{x}} \mathrm{O}_{4}(\mathrm{x}=0,1,2)$ spinels in aniline methylation. Catalysis Letters, 2012, 142(1): 7180.

[16] R. Spretz, S. Marchetti, M. Ulla, E. Lombardo. Fe/ $\mathrm{MgO}$ formulations for the catalytic combustion of methane. Journal of Catalysis, 2000, 194(2): 167174.

[17] J. S. Jang, S. J. Hong, J. S. Lee, P.H. Borse, OK. S. Jung, T. E. Hong, E. D. Jeong, M. S. Won, H. G. Kim. Synthesis of zinc ferrite and its photocatalytic application under visible light. Journal of the Korean Physical Society, 2009, 54(1): 204-208.

[18] M. Amiri, M. Salavati-Niasari, A. Akbari. Magnetic nanocarriers: Evolution of spinel ferrites for medical applications. Advances in Colloid and Interface Science, 2019, 265: 29-44.

[19] M.A. Malik, M.Y. Wani, M.A. Hashim. Microemulsion method: A novel route to synthesize organic and inorganic nanomaterials: 1st Nano Update. Arabian Journal of Chemistry, 2012, 5(4): 397-417.

[20] R. Rameshbabu, R. Ramesh, K. Samikannu, K. Annamalai, S. Ponnusamy. Synthesis and Study of Structural, Morphological and Magnetic Properties of $\mathrm{ZnFe} 2 \mathrm{O} 4$ Nanoparticles. Journal of Superconductivity and Novel Magnetism, 2014, 27: 1499-1502.

[21] R. Arulmurugan, B. Jeyadevan, G. Vaidyanathan, S. Sendhilnathan. Effect of zinc substitution on $\mathrm{Co}-\mathrm{Zn}$ and $\mathrm{Mn}-\mathrm{Zn}$ ferrite nanoparticles prepared by co-precipitation Journal of Magnetism and Magnetic Materials, 2005, 288: 470-477.

[22] S.U. Rather, O.M. Lemine. Effect of Al doping in zinc ferrite nanoparticles and their structural and magnetic properties. Journal of Alloys and Compounds, 2020, 812: 152058. 